\title{
GENETIC CONTROL OF THE MELANIC FORMS OF THE MOTHS DIURNEA FAGELLA AND ALLOPHYES OXYACANTHAE
}

\author{
R. C. STEWARD \\ Department of Zoology, University College of South Wales, Cardiff
}

Received 2.ix. 76

\section{SUMMARY}

\begin{abstract}
The melanic forms, dormoyella of the moth Diurnea fagella and capucina of the moth Allophyes oxyacanthae, are both controlled by single genes, completely dominant in expression to the respective typical phenotypes. The intermediate form of $A$. oxyacanthae is not inherited at the same locus as capucina. Distortions in the melanic: typical segregation ratios among the female progeny of some of the families of $A$. oxyacanthae indicate viability differences between the sexes which could possibly result in a difference between the relative fitnesses of heterozygous and homozygous capucina.
\end{abstract}

\section{INTRODUGTION}

THE melanic forms which increased in frequency in many moth species during the last century have almost always been found to be inherited at a single locus, with complete dominance of the melanic phenotype over the paler typical phenotype (Bowater, 1914; Onslow, 1921; Lees, 1974). In many species distinct forms, intermediate in darkness between the melanic and typical phenotypes, occur and in both Biston betularia (Glarke, and Sheppard, 1964; Lees, 1968) and Phigalia pilosaria (Lees, 1974) these are controlled at the same locus as the melanic forms. However, in both $P$. pilosaria (Lees, 1971) and Gonodontis bidentata (Kettlewell, 1959) there are " dark typical" forms which seem to be under polygenic control.

The work described in this paper was carried out to investigate the genetic control of $\mathrm{f}$. capucina of Allophyes oxyacanthae and $\mathrm{f}$. dormoyella of Diurnea fagella. Dr D. R. Lees (personal communication; Kettlewell, 1973) has reared families of $A$. oxyacanthae and obtained evidence that capucina is inherited as a single gene. No previous work on the genetics of the melanic forms of $D$. fagella seems to have been published.

\section{Genetic control of the Forms of $D$. fagella}

In the typical form the forewings are white or pale yellow and are overlaid with a speckling of black scales. In dormoyella, the wings are mainly black, with a fine scattering of white scales, a thin transverse white line and a white fringe on the outer margin of the wing. The rest of the body is also affected by the darkening. In addition there is an intermediate (or " dark typical ") form which is clearly distinct from dormoyella but which tends to overlap with the typical phenotype. In this intermediate form, dark speckling of the typical pattern is increased and there is a brown band across the middle of the forewing. 
The parentage and progeny of the families, which were all reared on beech (Fagus sylvatica), are shown in table l. If dormoyella is controlled by a single dominant gene, then the melanic offspring of $F / 1 / 73$ must have been heterozygotes. A cross between two melanics from this family produced a segregation of dormoyella and typical $(\mathrm{F} / 1 / 74)$ not significantly different from the expected $3: 1$ ratio, indicating that dormoyella is inherited as a simple Mendelian dominant. The segregations of approximately 1 melanic : 1 nonmelanic in $\mathrm{F} / 2 / 74$ and $\mathrm{F} / 3 / 74$ are consistent with this suggestion.

The segregation of intermediates and dormoyella in $\mathrm{F} / 2 / 74$ indicates that the phenotypes are clearly distinct. The variability in the intermediate phenotype suggests that it may represent polygenic darkening of the typical phenotype.

\section{Genetic control of the melanic forms of $A$. oxyacanthae}

In the typical form the forewings are light brown or brown, with paler oval markings and areas of green scales. In f. capucina the ground colour of the wings varies from chocolate-brown to blackish-brown and there are no green scales, although there may be a few scattered yellow scales. There is a distinct form, referred to as "intermediate" by Kettlewell (1973), which has uniform pale brown forewings with the areas of green scales of the typical form replaced by yellow scales.

The parents and progeny of the families, which were fed on hawthorn (Crataegus monogyna), are shown in table 2. The larvae were all reared under the same conditions in a cool, unheated room and fresh foliage was always present in the rearing containers.

In 1973, six crosses of capucina $\times$ typical were reared. Of these, five families $(0 / 1,0 / 3,0 / 5,0 / 11$ and $0 / 13)$ segregated for capucina and typical; in each family the ratio of capucina : typical was not significantly different from $1: 1$ (table 2). Two crosses were of melanic male $\times$ typical female, while the other three crosses were melanic female $\times$ typical male. The segregation of capucina and typical in both sexes in each family indicates that the inheritance of the capucina form does not involve $X$ or $Y$ linkage. The other family, $0 / 6$, produced 25 offspring, all capucina, indicating that capucina is controlled by a single dominant gene and that the melanic parent of $0 / 6$ was homozygous. This was confirmed by the segregation of capucina and typical in the five capucina $\times$ capucina crosses in 1974. In each family the segregation ratio was not significantly different from $3 \mathrm{M}: \mathrm{lT}$. In table 2 the segregation ratios for each family, and for the total progeny of several families involving the same type of mating, are tested against the expected segregation ratio (1: 1 or $3: 1$ ).

Examination of the variation in the darkness of the melanics in the families suggested that this was continuous. The melanic progeny of a " light" capucina parent showed a similar range in variation to the progeny of a "dark" capucina parent. Kettlewell (1973) states that a melanic form, darker than capucina, is spreading in some areas but all of the capucina seen in the British Museum (N.H.) Lepidoptera Collection were within the range of variation observed in the 22 families reported here. A similar range of darkness of the capucina phenotypes was observed in the capucina $\times$ typical families as was seen in the capucina $\times$ capucina families, indicating that capucina homozygotes are not darker than the heterozygotes. 


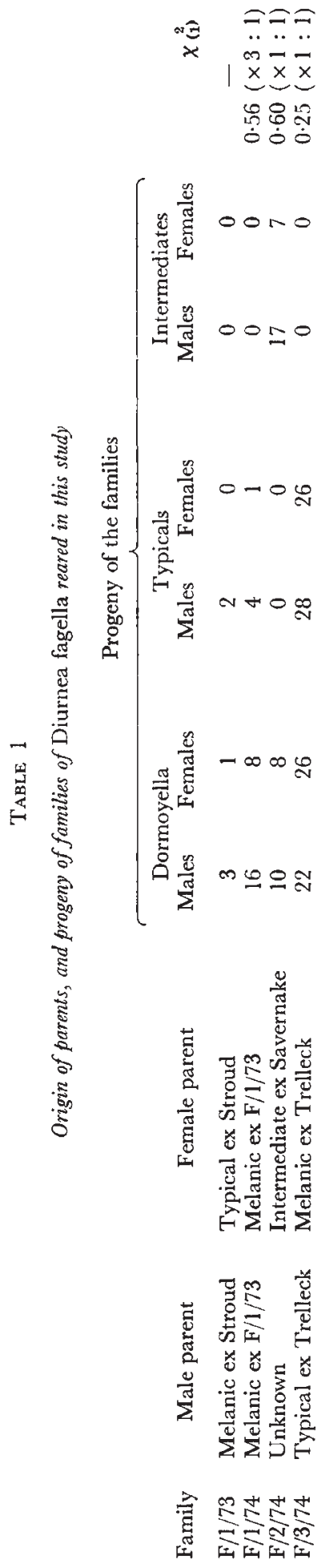




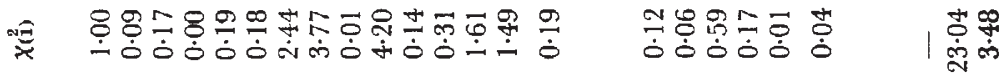

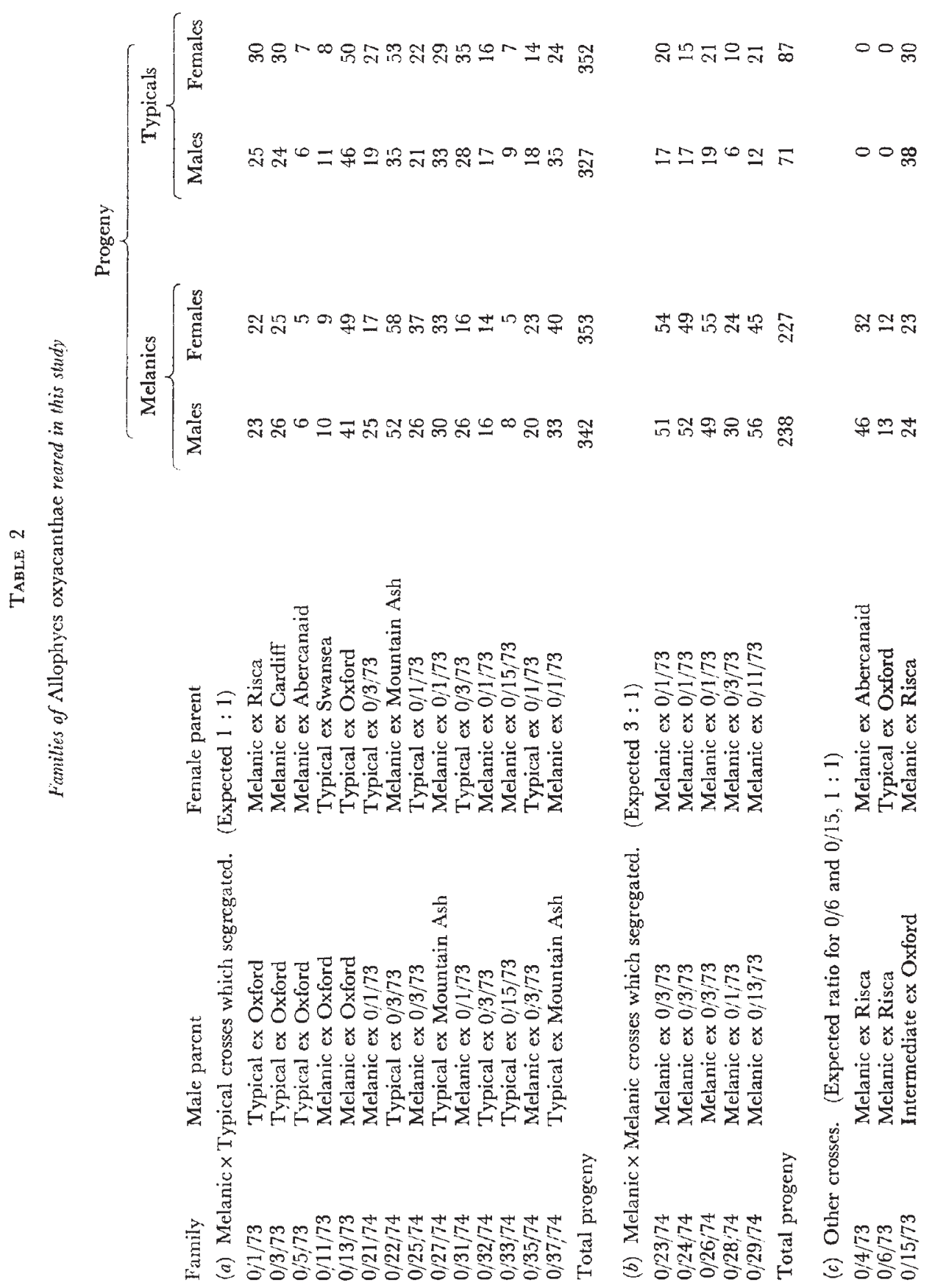


The male parent of $0 / 15$ was the only intermediate used as a parent in the matings. This specimen had uniform pale brown forewings with scattered yellow scales. The absence of green scales distinguishes the intermediate form from the normal range in variation of the typical phenotype, while the reflectance of the forewing clearly distinguishes the intermediate and capucina phenotypes. The forewing reflectances of a sample of six capucina and six typicals from $0 / 15$ and $0 / 13$, and of the intermediate parent of $0 / 15$, were measured using an S.E.I. exposure photometer. For capucina, the range in reflectance was from 5.0 per cent to 7.0 per cent and for typical the range was from 10.7 per cent to 18.0 per cent. The reflectance of the intermediate form was $10 \cdot 1$ per cent.

The segregation in $0 / 15$ was not significantly different from a $1: 1$ ratio of capucina : typical $\left(X_{1}^{2}=3 \cdot 48,0 \cdot 1>P>0.05\right)$. None of the progeny of $0 / 15$, nor of $0 / 33$, which resulted from a mating between two offspring of $0 / 15$, resembled the intermediate male parent of $0 / 15$. The failure of intermediates to segregate in either $0 / 15$ or $0 / 33$ indicates that this form is not controlled by another allele at the capucina locus. If the intermediate form were controlled by an allele, recessive to both capucina and typical, then $\frac{1}{4}$ of the offspring of $0 / 33$ would be expected to have been intermediate. The results indicate that the male parent of $0 / 15$ was genotypically " typical " and that the intermediate phenotype was produced by modifiers or environmental effects.

\section{Discussion}

The results for dormoyella and capucina are in agreement with Ford's (1937) suggestion that industrial melanism in the Lepidoptera will usually involve completely dominant melanic genes. Surveys in southern Britain indicate that both of these forms reach their highest frequencies in urban and industrial areas (Steward, 1977b). Ford (1937, 1940) suggests that melanic heterozygotes may have some physiological advantage over typicals but estimation of relative fitnesses of the genotypes from the results of laboratory rearing involves many problems.

For A. oxyacanthae, considering the totalled results for both sexes, there is no evidence of any consistent deviation from the expected l capucina : 1 typical segregation ratio among the progeny of the 14 crosses of capucina $\times$ typical (table 2a). Similarly, the five crosses of heterozygous capucina $\times$ heterozygous capucina (table $2 \mathrm{~b}$ ) show an overall segregation ratio not significantly different from the expected ratio of 3 capucina: 1 typical. However, if the segregation ratio within each sex is examined, there is evidence of important viability differences between the sexes.

The segregation ratio within each sex was tested against an expected 1 capucina : 1 typical ratio for each of the 14 crosses of heterozygous capucina $\times$ typical. The heterogeneity of the results for different families, calculated as the sum of the individual $X^{2}$ values, minus the $X^{2}$ value for the total progeny of the 14 families, was, for the females, $X_{13}^{2}=22.39(0.05>P>0.02)$, and for the males, $X_{13}^{2}=5.30(0.98>P>0.95)$. There is significant heterogeneity in the female segregation ratios of these families, although the pooled results show an almost exact 1 capucina : l typical ratio. Kettlewell (1973) has emphasised the need to consider the genetic origin of the moths used as parents when examining distortions in segregation ratios. 
The largest deviations from the expected $1: 1$ ratio, among the female progeny, occur in $0 / 25$, which shows an excess of melanic females, and in $0 / 31$, which shows an excess of typical females. There is evidence that the provenance of the moths affects the distortion in the female segregation ratio. Thus $0 / 25$ and $0 / 35$ both resulted from the mating, $0 / 3$ capucina $\times 0 / 1$ typical, and both produced more melanic females than typical females. 0/31,0/21 and $0 / 32$ resulted from the mating, $0 / 1$ capucina $\times 0 / 3$ typical, and each contained more typical females than melanic females. The total progeny resulting from these two types of matings are shown in table 3 . In both cases the deviation from the expected $1: 1$ segregation ratio, among the female progeny, is significant. In contrast, the male progeny show no significant deviation from a $1: 1$ ratio. The segregation ratio among the female progeny resulting from mating (a) in table 3 is significantly different

\section{TABLF 3}

Capucina : typical segregation ratios among the male and female progeny resulting from three types of mating: (a) $0 / 1$ capucina $\times 0 / 3$ typical; (b) $0 / 3$ capucina $\times 0 / 1$ typical; (c) $0 / 3$ capucina $\times 0 / 1$ capucina. The results which were combined to calculate the male and female segregation ratios are not significantly heterogeneous. The expected capucina : typical segregation ratios are for matings (a) and (b), $1: 1$ and for (c), $3: 1$

Families

(a) $0 / 21,0 / 31,0 / 32$

(b) $0 / 25,0 / 35$

(c) $0 / 23,0 / 24,0 / 26,0 / 28$

\begin{tabular}{|c|c|c|c|}
\hline \multicolumn{2}{|c|}{ capucina } & \multicolumn{2}{|c|}{ typical } \\
\hline Males & Females & Males & Females \\
\hline 67 & 47 & 64 & 78 \\
\hline 46 & 60 & 39 & 36 \\
\hline 182 & 182 & 59 & 66 \\
\hline
\end{tabular}

$* 0.05>P>0.01$
Segregation ratios (capucina $\div$ typical)

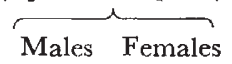

$1 \cdot 05$

$1 \cdot 18$

3.09

$0 \cdot 60$

$1 \cdot 67$

$2 \cdot 76$

\begin{tabular}{|c|c|}
\hline Males & Females \\
\hline $0 \cdot 03$ & $7 \cdot 20 * *$ \\
\hline $0 \cdot 42$ & $5 \cdot 51 *$ \\
\hline 0.01 & $0 \cdot 26$ \\
\hline
\end{tabular}

$\chi_{(1)}^{2}$ (against

$\overbrace{\text { Males Females }}^{\text {expected ratio) }}$

$0 \cdot 26$

from that among the males from the same families $\left(X_{1}^{2}=4 \cdot 26,0 \cdot 05>P>0 \cdot 02\right)$ and from that among females resulting from the other type of capucina $\times$ typical mating $\left(X_{1}^{2}=12.47, P<0.001\right)$.

The mating, $0 / 3$ capucina $\times 0 / 1$ capucina (table $3 \mathrm{c}$ ), will combine the genotypes resulting from the two types of capucina $\times$ typical mating and in these families neither males nor females show any significant deviation.

However, if the expected ratio of heterozygous capucina : typical among the progeny of these families is assumed to be $2: 1$, then it can be seen that the estimated ratio of homozygous capucina : typical for the females is $0.76: 1$ and for the males is $1.09: 1$. It is again the females which show the largest distortion. This indicates that, although the combined results for both sexcs may show close agreement with the expected segregation ratio, there may be important viability differences between males and females. These will have to be taken into account in any attempt to calculate relative fitness values for the melanic and typical genotypes from the rearing data. The expected ratio of heterozygous capucina : typical will itself be dependent on estimates of the relative fitnesses of these genotypes. Clarke and Sheppard (1963) have also found viability differences between the sexes in families of the moth, Biston betularia.

The differences bctween the segregation ratios among the female progeny 
of the two types of capucina $\times$ typical mating in table 3 correspond with differences between the resting site selection behaviour of capucina from these families (Steward, 1977a). The capucina offspring of the parental families, $0 / 1$ and $0 / 3$, also showed different resting behaviour (Steward, 1976). Analysis of the resting site selections of capucina from different families indicates that, while genetic differences between families seem to influence this behaviour, the variation cannot be explained as simply being the result of differences between the melanic alleles segregating in the families $0 / 1$ and $0 / 3$ (Steward, 1977a).

For Diurnea fagella, the small amount of rearing carried out so far neither demonstrates nor excludes viability differences between the melanic and typical genotypes. In $\mathrm{F} / 1 / 74$, the ratio of males : females is significantly different from $1: 1\left(X_{1}^{2}=4 \cdot 17,0.05>P>0.02\right)$. Both $\mathrm{F} / 1 / 74$ and $\mathrm{F} / 2 / 74$ show a deficiency of females suggesting that viability differences between the sexes may also be important in this species.

Acknowledgments. - I wish to thank Dr E. R. Creed for his many helpful comments on a draft of this paper. I also thank Dr D. R. Lees for many profitable discussions and for his help with the measurement of wing reflectance.

\section{RefERENGES}

Bowater, w. 1914. Heredity of melanism in Lepidoptera. 7. Genet., 3, 299-315.

ClARKE, C. A., AND SHEPPARD, P. M. 1963. Frequencies of the melanic forms of the moth Biston betularia (L.) on Deeside and in adjacent areas. Nature, Lond., 198, 1279-1282.

ClARKE, C. A., AND SHEPPARD, P. M. 1964. Genetic control of the melanic form insularia of the moth Biston betularia (L.). Nature, Lond., 202, 215-216.

FORD, E. B. 1937. Problems of heredity in Lepidoptera. Biol. Rev., 12, 461-503.

FORD, E. B. 1940. Genetic research in the Lepidoptera. Ann. Eugen., 10, 227-252.

KETTLEWELl, H. B. D. 1959. New aspects of the genetic control of industrial melanism in the Lepidoptera. Nature, Lond., 183, 918-921.

kettlewell, H. B. D. 1973. The Evolution of Melanism. Clarendon Press, Oxford.

LEES, D. R. 1968. Genetic control of the melanic form insularia of the peppered moth Biston betularia (L.). Nature, Lond., 220, 1249-1250.

LEES, D. R. 1971. The distribution of melanism in the Pale Brindled Beauty Moth, Phigalia pedaria, in Great Britain. In Ecological Genetics and Evolution, ed. by E. R. Creed, pp. 152-174. Blackwell, Oxford.

LEES, D. R. 1974. The genetic control of the melanic forms of the moth Phigalia pedaria (pilosaria). Heredity, 33, 145-150.

ONSLOW, THE HON. H. 1921. Inheritance of wing colour in Lepidoptera, VI. 7. Genet., 11, 277-292.

STEWARD, R. C. 1976. Experiments on resting site selection by the typical and melanic forms of the moth, Allophyes oxyacanthae (Caradrinidae). 7. Zool., Lond., 178, 107-115.

STEWARD, R. C. 1977a. Further experiments on resting site selection by the typical and melanic forms of the moth Allophyes oxyacanthae (Caradrinidae). F. Zool., Lond., 181, 395-406.

STEWARD, R. C. 1977b. Industrial melanism in the moths Diurnea fagella and Allophyes oxyacanthae. F. Zool., Lond. (in press). 